\title{
Awareness and Attitude of Women towards Cervical Cancer Screening in Abakaliki, South East Nigeria
}

\author{
J. O. Egede ${ }^{1}$, L. O. Ajah ${ }^{2}$, U. M. Agwu ${ }^{1}$, M. I. Ajah ${ }^{3}$, F. O. Edegbe ${ }^{4}$ J. N. Eze ${ }^{1} \&$ J. A. Obuna ${ }^{5}$ \\ ${ }^{1}$ Department of Obstetrics and Gynaecology, Alex Ekwueme Federal University Teaching Hospital, Abakaliki, \\ Nigeria \\ ${ }^{2}$ Department of Obstetrics and Gynaecology, University of Nigeria Nsukka, Enugu Campus, Nigeria \\ ${ }^{3}$ Institute of Maternal and ChildHealth, University of Nigeria Nsukka, Enugu Campus, Nigeria \\ ${ }^{4}$ Department of Pathology, Alex Ekwueme Federal University Teaching Hospital, Abakaliki, Nigeria \\ ${ }^{5}$ National Obsteric Fistula Centre, Abakaliki, Nigeria \\ Correspondence: Egede John Okafor, Department of Obstetrics and Gynaecology, Alex-Ekwueme Federal \\ University Teaching Hospital Abakaliki, Ebonyi State, Nigeria. Tel: 234-803-779-7950.
}

Received: September 26, 2020 Accepted: November 5, 2020 Online Published: March 15, 2021

doi:10.5539/gjhs.v13n4p115 URL: https://doi.org/10.5539/gjhs.v13n4p115

\begin{abstract}
Introduction: Cervical cancer screening has significantly contributed to the detection of premalignant and malignant lesions of the cervix and prevention of the morbidity and mortality associated with the disease. In the developing countries, especially sub-Saharan Africa where the burden of cervical cancer is highest, the high-risk population may not know the screening schedules or be able to pay for the services, and so fail to benefit.
\end{abstract}

Objective: To determine the level of awareness of cervical cancer screening schedule and willingness to pay for cervical screening services among women in Abakaliki, southeast Nigeria.

Method: The study design was a descriptive cross-sectional questionnaire-based and the population comprised 800 participants who came for free cervical cancer screening at well women centre, Alex Ekwueme Federal University Teaching Hospital, Abakaliki between January and December 2017. Data were analyzed using the Statistical Package for Sciences version 20.0.

Result: Of the $756(94.5 \%)$ questionnaires analyzed, the mean age was 41.4 years, modal parity $4 ; 83.6 \%$ had prior knowledge of cervical cancer while $81.0 \%$ knew that cervical cancer screening is a diagnostic tool. Surprisingly, only $32 \%$ of those aware of cervical cancer had previously done cervical cancer screening, while $10.8 \%$ knew the interval for cervical cancer screening. On screening for cervical cancer in future, $89.2 \%$ of the respondents were willing to repeat the test while $54.2 \%$ would be willing to pay for the screening services. Being 40 years of age or less, married, educated, of high socio-economic class and having first sexual intercourse at 18 years or less were associated with willingness to pay for screening.

Conclusion: Although the knowledge of cervical cancer is high, cervical cancer screening uptake is low, many women are aware of the interval for cervical cancer screening, and many will not be willing to pay for cervical cancer screening out of their pockets.

Keywords: cervical cancer, cervical cancer screening, screening interval, willingness to pay, Abakaliki, southeast Nigeria

\section{Introduction}

Cervical cancer is one of the leading malignancies among women worldwide and developing countries contribute over $80 \%$ of the global burden (Ajah, 2016). It is estimated that 70,722 new cases of invasive cervical cancer occur annually in sub-Saharan Africa (Bisi-Onyemaechi et al., 2018). About 50.33 million Nigerian women are at risk of cervical cancer and the crude incidence rate per 100,000 population is 17.1 while the age standardized incidence per 100,000 population is 29.0 (WHO, 2014). GLOBOCAN 2018 estimate showed 14,943 new cases and 10,403 deaths annually and a woman's lifetime risk of developing and dying as a result of invasive cervical cancer in Nigeria are 2.1\% and 1.7\%, respectively (GLOBOCAN, 2018; Egede et al., 2018; Garg, 2011). 
Cervical cancer is a highly preventable and curable disease when detected and treated early in its premalignant stage. The prolonged phase of the premalignant stage of the cervical cancer and accessibility of the cervix provides the opportunity for screening to detect the disease at the pre-invasive state thereby allowing for early treatment and cure (Bakari et al., 2015). The high cervical cancer burden in our environment therefore has been ascribed to ignorance, lack of resources, limited access to health care and cervical cancer screening facilities and unavailability of nationally organized screening programs (Bakari et al., 2015; Onah et al.,2001)

Screening using mainly Pap smear cytology and visual inspection with acetic acid or Lugol's iodine remain essentially opportunistic (Ajah, 2016). Even the opportunistic screening is not widely available. It is also less effective because it mainly targets a small proportion of women who have the opportunity to come in contact with health care providers either in a health facility or in the community (Okunoyo et al., 2018; Owoeye \& Ibrahim, 2013). Even when facilities are available, utilization has remained poor (Bakari et al., 2015).

Regular, systematic and organized mass screenings for cervical cancer targeted at all women at risk, as being implemented by developed countries, have resulted in over $80 \%$ reduction of morbidity and mortality associated with cervical cancer (Egede et al., 2018; Okunowo et al., 2018; Peirson et al., 2013). Approximately 5\% of eligible women in the developing countries undergo screening for cervical cancer (Egede et al., 2018). Therefore majority of those who develop and die of cervical cancer have never been screened. Unfortunately most of these women may not be aware of the screening schedule.

Despite various efforts that have been put in place to improve awareness of cervical cancer by women in developing countries, uptake has largely remained low. Some of the identified factors that influence uptake of cervical cancer screening include age of the women, their marital status, parity, low perception of risk of developing cervical cancer, lack of knowledge about symptoms of the disease and the benefits of screening, financial constraint and knowing someone who has cancer of the cervix (Butho et al., 2013; Ndikom \& Ofi, 2012). Previous study in 2012 done at Afikpo, a semi urban town in Ebonyi state, revealed that $37.5 \%$ were aware of cervical cancer screening, uptake of cervical cancer screening was $0.6 \%$ and $62 \%$ of those who screened were willing to be screened again (Eze et al., 2012). However this study was weakened by unavailability of awareness of the screening interval and willingness of the participants to pay for the subsequent screening. Similar studies in Lagos, Maiduguri and Ibadan showed high awareness and low utilization of cervical cancer screening (Okunowo et al., 2018; Bakari et al., 2015; Ndikom \& Ofi, 2012). However, none of these studies looked into willingness to pay for screening and knowledge of screening interval.

The aim and objectives of this study were:

1). To assess the level of awareness and knowledge of cervical cancer among women attending free cervical cancer screening in a teaching hospital.

2). To determine their attitude towards cervical cancer screening including willingness to pay among the participants.

3). To determine factors influencing uptake of screening programme among the participants.

\section{Materials and Methods}

\subsection{Study Design}

This was a questionnaire-based descriptive cross-sectional study involving women who attended free cancer screening organized by the hospital at the well Women centre, AEFUTHA between January 2017 and December 2017.

Sample size for the participants was determined by formula for estimation of sample size in cross sectional studies, (Charan \& Biswas, 2013) at 95\% confidence interval and taking 5\% level of precision. The sample size was calculated by using the $37 \%$ prevalence from a previous study in Afikpo (Eze et al., 2012) and it was 358. In order to increase the validity of the study, $\mathrm{N}$ was increased by $100 \%$ and attrition rate of $10 \%$ was added. This was rounded up to 800 participants.

The participants were recruited consecutively until the desired sample size was reached. The purpose of the study and sections of the questionnaire were fully explained to the participants and informed consent was obtained from them. Thereafter, the participants were interviewed using structured self-administered questionnaire. However, the participants who could not read English language were assisted by trained research assistants. Those who declined consent to participate in the study, were excluded and the incompletely filled questionnaires were further excluded from data collation and analysis. The questionnaire was pretested on women who attended voluntary cervical cancer screening at National Obstetric Fistula Centre, Abakaliki. 
The questionnaire was structured to collect information on the respondents' socio-demographic characteristics, sexual history, knowledge of cervical cancer, source of their information, prior cervical cancer screening, knowledge about the screening interval and willingness to pay and participate in subsequent screenings. The data obtained were analyzed using Statistical Package for Social Sciences (IBM SPSS, Armonk, New York), version 20.0. The obtained data were presented as frequencies and percentages for categorical variables and mean and standard deviation for continuous variables. Inferential statistics was used to establish relationship between the socio-demographic characteristics and willingness to pay for cervical cancer screening. The level of significance was put at $\mathrm{P} \leq 0.05$

The ethical clearance for the study was obtained from the Health Research and Ethics Committee of AEFUTHA.

\section{Result}

A total of 756 of the 800 questionnaires applied were analyzed giving a response rate of $94.4 \%$.

Table 1 depicts the socio-demographic characteristics of the respondents. The 31 to 40 years age group was the largest, $45.2 \%$, and 61 years and above the least; the mean age of the participants was $41.3 \pm 9.5$ years. Multiparous women comprised the largest parity group, $65.6 \%$ and nulliparae the least, $34.4 \%$; the mean parity was $3.7 \pm 2.5$. A total of $77.8 \%$ of the participants were married, $82.3 \%$ were in social class 3 and below, and $59.5 \%$ attained tertiary education.

Table 1. Socio-demographic characteristics of the respondents

\begin{tabular}{|c|c|c|}
\hline Socio-demographic characteristics & Frequency & Percentage (\%) \\
\hline \multicolumn{3}{|l|}{ Age(years) } \\
\hline $21-30$ & 72 & 9.5 \\
\hline $31-40$ & 342 & 45.2 \\
\hline $41-50$ & 226 & 29.9 \\
\hline $51-60$ & 80 & 10.6 \\
\hline$>60$ & 36 & 4.8 \\
\hline \multicolumn{3}{|l|}{ Mean $41.3 \pm 9.5$} \\
\hline \multicolumn{3}{|l|}{ Parity } \\
\hline Nullipara & 60 & 34.4 \\
\hline $1-4$ & 152 & 20.1 \\
\hline$\geq 5$ & 344 & 45.5 \\
\hline \multicolumn{3}{|l|}{ Mode $=4$, mean $=3.7 \pm 2.5$} \\
\hline \multicolumn{3}{|l|}{ Marital Status } \\
\hline Single & 80 & 10.6 \\
\hline Married & 588 & 77.8 \\
\hline Widowed & 72 & 9.5 \\
\hline Divorce & 10 & 1.3 \\
\hline Separated & 6 & 0.8 \\
\hline \multicolumn{3}{|l|}{ Social class } \\
\hline Class1 & 190 & 25.2 \\
\hline Class2 & 224 & 29.6 \\
\hline Class3 & 208 & 27.5 \\
\hline Class4 & 54 & 7.2 \\
\hline Class5 & 80 & 10.6 \\
\hline \multicolumn{3}{|l|}{ Educational status } \\
\hline None & 46 & 6.1 \\
\hline Primary & 90 & 11.6 \\
\hline Secondary & 170 & 22.5 \\
\hline Tertiary & 450 & 59.5 \\
\hline
\end{tabular}


Table 2 shows the respondents' sexual history. Four hundred and six of the respondents or $53.7 \%$ had first sexual intercourse before 18 years; the mean age at the sexual debut of 19.1 years; $55.3 \%$ had had more than one sexual partner, and $39.9 \%$ knew that their husbands or spouses had had more than one sexual consort.

Table 2. Sexual history of the respondents

\begin{tabular}{lll}
\hline Sexual history & Frequency & Percentage \\
\hline Age at first sexual intercourse(years) & & \\
$\leq 10$ & 4 & 0.5 \\
$11-15$ & 126 & 16.7 \\
$16-20$ & 390 & 51.6 \\
$21-25$ & 206 & 27.2 \\
$26-30$ & 28 & 3.7 \\
$>30$ & 2 & 0.3 \\
Mean age at fist sexual intercourse:19.1 $\mathbf{3 . 9} ;$ & & \\
Ever had $>\mathbf{1}$ sexual partner & & \\
No & 338 & 35.4 \\
Yes & 418 & 55.3 \\
Husband ever had $>\mathbf{1}$ sexual partner & & \\
No & 268 & 35.4 \\
Yes & 302 & 39.9 \\
Not sure & 196 & 24.6 \\
\hline
\end{tabular}

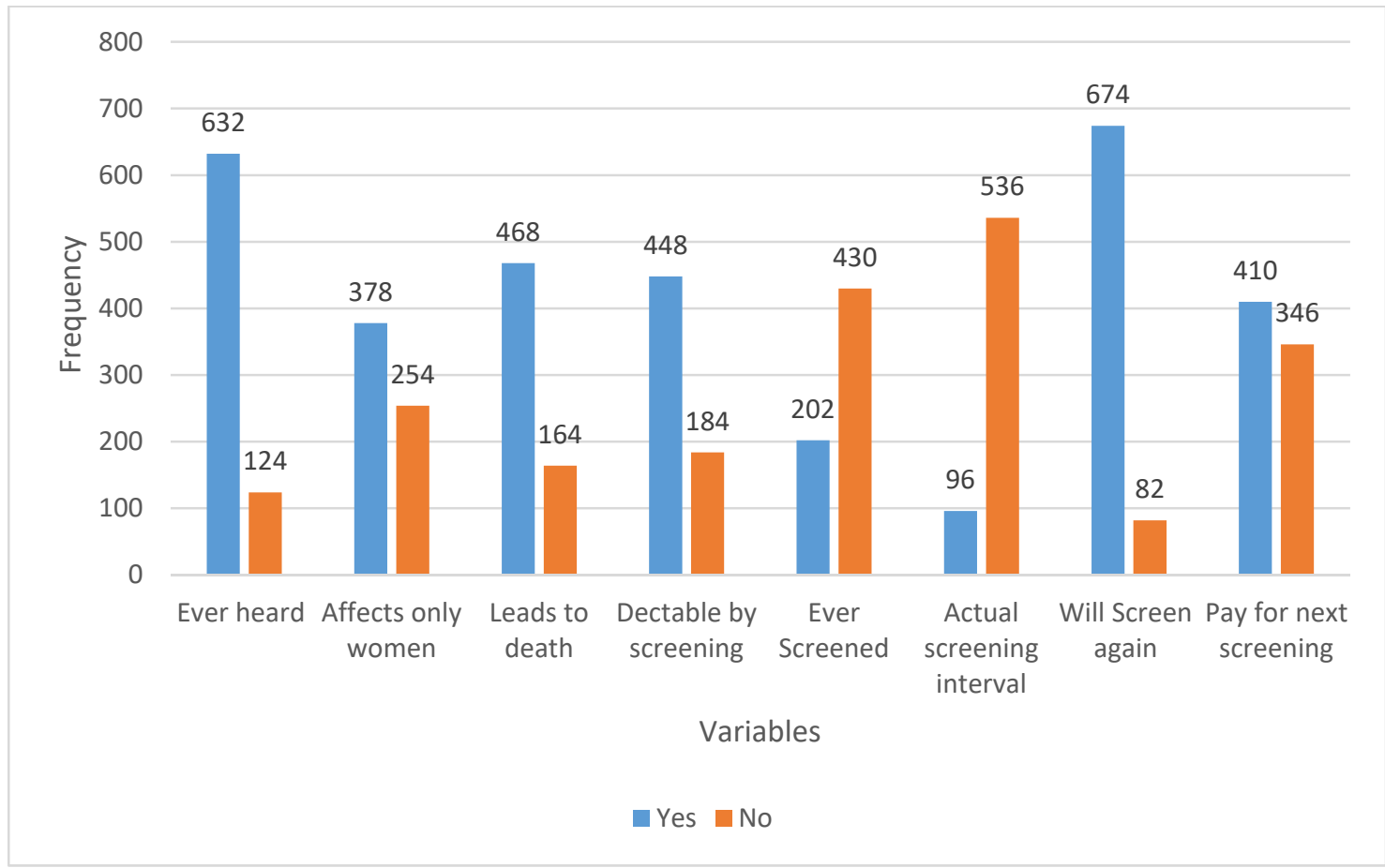

Figure 1. Awareness and Uptake of Cervical Cancer and its Screening by Respondents 
Table 3. Respondents' source of information on cervical cancer, $\mathrm{N}=632(100 \%)$

\begin{tabular}{lll}
\hline Source of information & Frequency & Percentage \\
\hline Health workers (Doctors, Nurses, etc.) & 306 & 49.1 \\
Friends & 176 & 28.3 \\
Churches & 111 & 17.8 \\
Electronic media & 109 & 17.5 \\
Family members & 28 & 4.5 \\
Print media & 26 & 4.2 \\
\hline
\end{tabular}

Figure 1 and Table 3 display the respondents' knowledge of cervical cancer, the sources of their awareness, the things they know about cervical cancer and their history of cervical cancer screening. Majority of the respondents, 632 or $83.6 \%$, had heard of cervical cancer; some of them from multiple sources. Health workers, $49.1 \%$, were the most common source of information, followed by friends, $28.3 \%$, and churches; the print media was the least common source at $4.2 \%$. Three hundred and seventy-eight respondents or $59.8 \%$ knew that cervical cancer affects women, $74.1 \%$ knew that cervical cancer leads to death, $70.1 \%$ knew that it was detectable by screening and $15.2 \%$ knew the screening interval. A total of 202 respondents or $32.0 \%$ had previously had cervical cancer screening. Overall, 674 respondents or $89.2 \%$ indicated that they would be willing to repeat cervical cancer screen in the future while 410 or $54.2 \%$ showed that they would be willing to pay for future screening.

Table 4 shows the relationship between respondents' socio-demographic variables and their willingness to pay for cervical cancer screening in the future. Being 40 years old or less, and being married, educated and of socio-economic class 2 or less, and having had first sexual intercourse at less than 18 years of age were statistically significantly associated with willingness to pay for cervical cancer screening in the future with $\mathrm{P}$ values $<0.05$ at $95 \%$ CI.

Table 4. Association between respondents' socio-demographic variables and their willingness to pay for screening in the future

\begin{tabular}{|c|c|c|c|c|}
\hline \multicolumn{5}{|c|}{ Willingness to pay } \\
\hline Variable & Yes & No & AOR (CI) & P value \\
\hline \multicolumn{5}{|l|}{ Age (Years) } \\
\hline$\leq 40$ & 247 & 167 & $0.674(0.486-0.933)$ & $0.010^{*}$ \\
\hline$>40$ & 163 & 179 & & \\
\hline \multicolumn{5}{|l|}{ Parity } \\
\hline$\leq 4$ & 274 & 222 & $0.901(0.628-1.294)$ & 0.572 \\
\hline$>4$ & 136 & 346 & & \\
\hline \multicolumn{5}{|l|}{ Marital status } \\
\hline Married & 356 & 232 & $0.278(0.186-0.417)$ & $0.000^{*}$ \\
\hline Unmarried & 54 & 114 & & \\
\hline \multicolumn{5}{|l|}{ Social status } \\
\hline$\leq 2$ & 251 & 164 & $0.567(0.393-0.818)$ & $0.002^{*}$ \\
\hline$>2$ & 159 & 182 & & \\
\hline \multicolumn{5}{|c|}{ Educational status } \\
\hline Uneducated & 55 & 81 & $1.328(0.763-2.093)$ & 0.364 \\
\hline Educated & 355 & 265 & & \\
\hline \multicolumn{5}{|c|}{ Age (Years) at first sexual intercourse } \\
\hline$<18$ & 260 & 146 & $0.328(0.238-0.453)$ & $0.000^{*}$ \\
\hline$\geq 18$ & 150 & 200 & & \\
\hline
\end{tabular}

$\mathrm{AOR}=$ Adjusted Odds Ratio; * statistically significant; $\mathrm{CI}=95 \%$ confidence interval. 


\section{Discussion}

Cervical cancer remains an egregious threat to women's health and lives, with a woman losing her life to it every other minute globally; a suffering that is unacceptable for a preventable disease (World Health Organization, 2018). The mean age of the respondents in this study of 41 years shows that most of them fell within the age group that could benefit from an organized cervical cancer screening program were it to be available. Suffice it to say that the guidelines for the prevention of cervical cancer in Nigeria (Akinola, Aimakhu, Ezechi, \& Fasubaa, 2018) targets screening women aged 25 to 65 years. Also, all the women in this study had been sexually active, more than $50 \%$ of them had sexual debut before 18 years, entertained multiple sexual partners and were parous, and about $40 \%$ of their consorts had sex with more than one sexual partner. Sexual intercourse with multiple sexual partners or with consorts that have many sexual partners and early sexual debut expose women to infection by Human Papillomavirus infection, the causative agent of cervical cancer (Ifemelumma et al., 2019; Bisi-Onyemaechi, Chikani, \& Nduagubam, 2018; Toye et al., 2017; Eze et al., 2012).

Low awareness of cervical cancer amongst women is an identified barrier to cervical cancer screening uptake (Okunowo et al., 2018; Idowu et al., 2016). More than $80 \%$ of the participants were aware of cervical cancer, including some of its modes of presentation and complications, and screening for cervical cancer. Thus, the awareness level documented is higher than the $37.5 \%$ awareness reported from Afikpo in the same Ebonyi State southeast Nigeria (Eze et al., 2012), 18.7\% and 67\% from Ibadan and Ogbomoso in southwest Nigeria (Kene, Saleh, \& Nandul, 2006; Idowu et al., 2016) and 67.3\% from Zaria, northwest Nigeria (Yahya \& Mande, 2019), but similar to the findings of cervical cancer awareness of $79.8 \%, 64.0 \%, 80.0 \%, 72.9 \%, 94.0 \%$ in Nnewi in the southeast, Benin in the south-south, Lagos in the southwest, Jos in the north-central, and Maiduguri in the northeast respectively (Udigwe, 2006; Gharoro \& Ikeanyi, 2006; Okunowo et al., 2018; Oyebode, Sagay, Ekwempu, \& Daru, 2006; Bakari, Takai, \& Bukar, 2015). This study shows that $32 \%$ of the participants who were aware of cervical cancer had undergone cervical cancer screening in the past. This finding is a marked improvement on the $0.6 \%$ cervical cancer screening uptake reported by an earlier study from Afikpo in Ebonyi State (Eze et al., 2012). It is also noteworthy that the $32 \%$ cervical cancer screening uptake among participants aware of cervical cancer in this study is higher than the $1.5 \%$ and the $8 \%$ reported from Ogbomoso in southwest Nigeria (Idowu et al., 2018) and Zaria (Yahya \& Mande, 2019) respectively. These findings show that an increase in cervical cancer awareness increases cervical cancer screening uptake. Thus, more women getting screened for cervical cancer brings us closer to reducing the incidence of cervical cancer in line with the evidence that regular well-organized smear testing curbs cervical cancer's menace (Comparreto \& Borruto, 2015). The differences in the reported values may be as a result of the educational and social status of our respondents which were mostly tertiary education and high social class. Besides, this was a hospital-based study and may not be representative of the awareness level of women in the community (Idowu et al., 2016). The awareness levels of cervical cancer and its screening modalities are still highly variable among Nigerian women. For there to be a significant gain in the prevention of cervical cancer in Nigeria, this narrative needs to change; there is a need for aggressive public awareness education (Eze et al., 2012; Olubodun, Odukoya, \& Balogun, 2019).

The sources of knowledge about cervical cancer in this study were mainly from health workers and friends, with smaller contributions from the church and electronic and print media. It is noteworthy that in reproductive health, information obtained from friends is more likely to be incorrect as it may contain a lot of misinformation, distortion, falsehoods and misconception (Egede et al., 2015). Also worthy of note is that the anxiety associated with cervical cancer screening results from insufficient information, distortion or magnification of different facts (Patra, Upadhyay, \& Chhabra, 2014). There is a need to disseminate the correct information about cervical cancer screening which is sensitive to our religious and cultural context. Social media, mass media and commercials can be used as veritable tools to continue awareness creation about cervical malignancy (Patra, Upadhyay, \& Chhabra, 2014).

The uptake of cervical cancer screening in this study was low. Only $32 \%$ (less than $27 \%$ of all the respondents) of those aware of cervical cancer had ever undergone cervical cancer screening, and about $15 \%$ of them were aware of the screening interval. These findings are higher than the reports from Afikpo, Lagos, Ilorin, India and Sri Lanka where $0.6 \%, 5.1 \%, 8.0 \%, 7.3 \%$ and $18.1 \%$ respectively had done cervical cancer screening (Eze et al.; 2012, Wright, Aiyedehin, Akinyinka, Ilozumba, 2014; Idowu et al., 2014 Singh, Rajan, Das, Gupta, 2016; Shivanthan, et al., 2014). However, they compare poorly with the reports from among Turkish and Gabonese women showing that $73 \%$ and $65.1 \%$ respectively had done Pap smear screening (Karadag et al., 2014; Assoumou et al., 2015). The possible reason for the difference between the uptake of cervical cancer screening in this study and the previous reports in Nigeria may be due to the predominant high educational status and social 
class as well as the urban residence of most of the respondents. This study, done at a teaching hospital in the state capital, contrasts with other Nigerian studies which were conducted mainly among women in rural areas where there could be lack of information with the unavailability of screening facilities (Eze et al., 2012). The low uptake of cervical cancer screening among the predominantly high social class women in this study underscores the need for massive health education of the populace on cervical cancer and its screening modalities.

Although there are regional variations in the schedule for cervical cancer screening, the standard remains the recommendation by WHO on commencement of cervical cancer screening as a form of secondary prevention from the age of 25 years. The United States Preventive Services Task Force and the joint partnership of American Cancer Society, American Society for Colposcopy and Cervical Pathology, and American Society for Clinical Pathology (ACS/ASCCP/ASCP), recommend 3-yearly cervical cytology screening for women aged 2129 years, and 5-yearly cytology and HPV co-testing or 3-yearly cytology alone for those above 30 years. And, women who have reached 65 years and had remained negative following regular cervical cancer screening over the preceding ten years, should discontinue screening (Moyer, 2014). The Society of Gynaecologists and Obstetricians on Nigeria has guidelines for the prevention of cervical cancer in Nigeria ((SOGON, 2017; Akinola, Imakhu, Ezechi, \& Fasubaa, 2018), which their implementation has been hampered by inadequate infrastructure, ignorance, lack of skilled personnel and poverty.

\subsection{Limitation}

There are some limitations to this study. The research was hospital-based. Thus, the findings may not necessarily reflect the reality in the communities and the entire Ebonyi state. Also, the study design was cross-sectional with convenience sampling, making it difficult to generalize the results obtained to the whole population. Besides, some of the information sought from the respondents could be affected by recall bias.

\section{Conclusion}

Although there is high knowledge of cervical cancer and its screening, there is still low and lower willingness to pay for services towards the uptake of cervical cancer screening among women in Abakaliki, southeast Nigeria.

\subsection{Recommendation}

There is a need for more aggressive advocacy and dissemination of information about cervical cancer and its screening. Also, there is a need for concerted efforts at the elimination of out-of-pocket payments for cervical cancer screening as a way of encouraging women to access it. Additionally, there is a need for the expansion of the ongoing sporadic cervical cancer screening as means of increasing uptake and to install a regular and organized screening program targeting all women. Government, non-governmental organizations, philanthropists and policymakers should be fully involved in reversing the ugly trend of low cervical cancer screening in this environment.

\section{Competing Interests Statement}

The authors declare that there are no competing or potential conflicts of interest.

\section{References}

Ajah, L. O. (2016). Colposcopy and its challenges in Nigeria. Ann Trop Med Public Health, 9, 379-80. https://doi.org/10.4103/1755-6783.193936

Assoumou, S. Z., Mabika, B. M., Mbiguino, A. N., Mouallif, M., Khattabi, A., \& Ennaji, M. M. (2015). Awareness and knowledge regarding of cervical cancer, Pap smear screening and human papillomavirus infection in Gabonese women. BMC women's health, 15(1), 1-7. https://doi.org/10.1186/s12905-015-0193-2

Akinola, O. I., Aimakhu, C. O., Ezechi, O. C., \& Fasubaa, O. B. (2018). Society of obstetrics and gynecology of Nigeria-Clinical practice guidelines: Guidelines for the prevention of cervical cancer. Tropical Journal of Obstetrics and Gynaecology, 35(3), 371-376. https://doi.org/10.4103/TJOG.TJOG_88_18

Bakari, M., Takai, I. U., \& Bukar, M. (2015). Awareness and utilization of Papanicoloau smear among health care workers in Maiduguri, Nigeria. Nigerian Journal of Basic and Clinical Sciences, 12(1), 34. https://doi.org/10.4103/0331-8540.156682

Bisi-Onyemaechi, A. I., Chikani, U. N., \& Nduagubam, O. (2018). Reducing incidence of cervical cancer: knowledge and attitudes of caregivers in Nigerian city to human papilloma virus vaccination. Infectious agents and cancer, 13(1), 1-6. https://doi.org/10.1186/s13027-018-0202-9

Ncube, B., Bey, A., Knight, J., Bessler, P., \& Jolly, P. E. (2015). Factors associated with the uptake of cervical cancer screeningamong women in Portland Jamaica. North American Journal ofMedical Sciences, 7(3), 
104-113. https://doi.org/10.4103/1947-2714.153922

Charan, J., \& Biswas, T. (2013). How to Calculate Sample Size for Different Study Designs in Medical Research? Indian journal of psychological medicine, 35(2) 121-126. https://doi.org/10.4103/0253-7176.116232

Comparetto, C., \& Borruto, F. (2015). Cervical cancer screening: A never-ending developing program. World $J$ Clin Cases, 3(7), 614-624. https://doi.org/10.12998/wjcc.v3.i7.614

Egede, J. O., Onoh, R. C., Umeora, O. U., et al. (2015). Contraceptive prevalence and preference in a cohort of south-east Nigerian women. Patient Preference and Adherence, 9, 707-714. https://doi.org/10.2147/PPA.S72952

Egede, J., Ajah, L., Ibekwe, P., Agwu, U., \& Nwizu, E. (2018). Comparison of Accuracy of Papanicolaou Test Cytology, Visual Inspection with Acetic and Visual Inspection with Lugol Iodine in Screeing for Cervical Neoplasia in Southeast Nigeria. J Glob Oncol., 4. https://doi.org/10.1200/JGO.17.00127

Eze, J. N., Umeora, O. U., Obuna, J. A., Egwuatu, V. E., \& Ejikeme, B. N. (2012). Cervical cancer awareness and cervical screening uptake at the Mater Misericordiae Hospital, Afikpo, Southeast Nigeria. Ann Afr Med, 11, 238-43. https://doi.org/10.4103/1596-3519.102856

Ezugwu, E. C., Mutihir, J. T., \& Daru, P. H. (2006) Knowledge, attitude and practice of Pap smear cervical screening among antenatal patients at Jos University Teaching Hospital, Jos, Nigeria. J Med Trop, 8, 1-8. https://doi.org/10.4314/jmt.v8i2.35192

Garg, P. (2011). Evaluation of visual inspection with acetic acid (VIA) \& visual inspection with Lugol's iodine (VILI) as a screening tool for cervical intraepithelial neoplasia in comparison with cytologic screening. Webmed Central Obstetrics and Gynaecology 2:WMC001971.

Gharoro, E. P., \& Ikeanyi, E. N. (2006). An appraisal of the level of awareness and utilization of pap smear as cervical cancer screening test among female health workers in a tertiary health institution. International Journal of Gynecological Cancer, 16, 1063-8. PMid:16803486. https://doi.org/10.1111/j.1525-1438.2006.00579.x

GLOBOCAN. (International Agency for Research on Cancer) Fact Sheet 2018.

ICO/IARC Information Centre on HPV and Cancer. (2019). Nigeria. Human Papillomavirus and Related Cancers, Fact Sheet 2018. Retrieved from https://www.hpvcentre.net/statistics/reports/NGA_FS.pdf

Idowu, A., Olowookere, S. A., Fagbemi, A. T., \& Ogunlaja, O. A. (2016). Determinants of Cervical Cancer Screening Uptake among Women in Ilorin, North Central Nigeria: A Community-Based Study. Journal of Cancer Epidemiology, 2016, Article ID 6469240, 8. https://doi.org/10.1155/2016/6469240

Ifemelumma, C. C., Anikwe, C. C., Okorochukwu, B. C., et al. (2019). Cervical cancer screening: assessment of perception and utilization of services among health workers in low resource setting. International Journal of Reproductive Medicine, Article ID 6505482, 8. https://doi.org/10.1155/2019/6505482

Karadag, G., Gungormus, Z., Surucu, R., et al. (2014). Awareness and practices regarding breast and cervical cancer among Turkish women in Gazientep. Asian Pacific Journal of Cancer Prevention, 15(3) 1093-1098. https://doi.org/10.7314/APJCP.2014.15.3.1093

Kene, T. S., Saleh, M. I., \& Nandul, L. D. (2006). Cervical cancer screening: What the female teachers need to know. Trop J Obstet Gynaecol, 23(Suppl 1), S22.

Moyer, V. A. (2012). Screening for cervical cancer: U.S. Preventive services task force recommendation statement. Ann Intern Med, 156, 880 91, W312. https://doi.org/10.7326/0003-4819-156-12-201206190-00424

Ndikom, C. M., \& Ofi, A. (2012). Awareness, perception and factors affecting utilization of cervical cancer screening services among women in Ibadan, Nigeria: a qualitative study. Reprod Health, 9, 11. https://doi.org/10.1186/1742-4755-9-11

Nyengidiki, T. K., Inimgba, N., Bassey, G., \& Ogu, R. N. (2019). Does introduction of user fees affect the utilization of cervical cancer screening services in Nigeria? Niger $J$ Clin Pract, 22, 745-9. https://doi.org/10.4103/njcp.njcp_257_18

Onah, H. E., Ezugwu, F. O., \& Eze, J. N. (2001). Cervical cancer screening; A survey of current practice amongst Nigerian gynaecologist. Tropical Journal of Obstetrics and Gynaecology, $18,78 \quad 81$. https://doi.org/10.4314/tjog.v18i2.14435

Okunowo, A. A., Daramola, E. S., Soibi-Harry, A. P. et al. (2018). Women's knowledge of cervical cancer and 
uptake of Pap smeartesting and the factors influencing it in a Nigerian tertiary hospital. JCRP, 5, 105e111 https://doi.org/10.1016/j.jcrpr.2018.02.001

Olubodu, T., Odukoya, O. O., \& Balogun, M. R. (2019). Knowledge, attitude and practice of cervical cancer prevention, among women residing in an urban slum in Lagos, South West, Nigeria. Pan African Medical Journal, 32, 130. https://doi.org/10.11604/pamj.2019.32.130.14432

Owoeye, I. O., \& Ibrahim, I. A. (2013). Knowledge and attitude towards cervical cancer screening among female students and staff in a tertiary institution in the Niger Delta. International Journal of Med Biomed Research, 2, 48e56. https://doi.org/10.14194/ijmbr.219

Oyebode, T. A., Sagay, S. A., Ekwempu, C. C., \& Daru, P. H. (2006). The possible role of the gynaecologist in the poor awareness and non utilization of the Pap smear among female health workers. Trop J Obstet Gynaecol, 23, S20(Suppl 1).

Patra, S., Upadhyay, M., \& Chhabra, P. (2014). Awareness of cervical cancer and willingness to participate in screening program: Public health policy implications. Journal of Cancer Research and Therapeutics, 13, 318-323. https://doi.org/10.4103/0973-1482.187279

Peirson, L., Fitzpatrick-Lewis, D., Ciliska, D., \& Warren R (2013). Screening for cervical cancer: a systematic review and meta-analysis. Syst Rev, 2, 35. https://doi.org/10.1186/2046-4053-2-35

Shivanthan, M. C., Arunakiri, K., Wickramasinghe, S. I., et al. (2014). Low uptake of Pap smear testing among medical clinic attendees in a tertiary care hospital in Sri Lanka. International Health, 6(2), 138-143. https://doi.org/10.1093/inthealth/ihu021

Singh, M., Ranjan, R., Das, B., \& Gupta, K. (2014). Knowledge, attitude and practice of cervical cancer screening in women visiting a tertiary care hospital of Delhi. Indian Journal of Cancer, 51(3) 319-323. https://doi.org/10.4103/0019-509X.146780

Toye, M. A., Okunade, K. S., Roberts, A. A., et al. (2017). Knowledge, perceptions and practice of cervical cancer prevention among female public secondary school teachers in Mushin local government area of Lagos State, Nigeria. Pan African Medical Journal; 28, 221. https://doi.org/10.11604/pamj.2017.28.221.13980

Udigwe, G. O. (2006). Knowledge, attitude and practice of cervical cancer screening (Pap. Smear) among female nurses in Nnewi, South Eastern Nigeria. Nigerian Journal of Clinical Practice, 9, 40-43. PMID: 1698628

Wright, K. O., Aiyedehin, O., Akinyinka, M. R., \& Iluzumba, O. (2014). Cervical cancer: community perception and preventive practices in an urban neighborhood of Lagos (Nigeria). ISRN Preventive Medicine, 950534, 9. https://doi.org/10.1155/2014/950534

World Health Organization, Nigeria. (2014). Human Papillomavirus and Related Cancers, Fact Sheet 2014. WHO/ICO HPV Information Centre.

World Health Organization. (2018 September). WHO leads the way towards the elimination of cervical cancer as a public health concern. https://www.who.int/reproductivehealth/cervical-cancer-public-health-concern/en/

Yahya, A., \& Mande, A. T. (2019). Awareness and knowledge of cervical cancer and its screening methods among women attending primary healthcare centers in Zaria, North Western, Nigeria. Tropical Journal of Obstetrics and Gynaecology, 36, 271-276. https://doi.org/10.4103/TJOG.TJOG_26_19

\section{Copyrights}

Copyright for this article is retained by the author(s), with first publication rights granted to the journal.

This is an open-access article distributed under the terms and conditions of the Creative Commons Attribution license (http://creativecommons.org/licenses/by/4.0/). 